Brit. J. industr. Med., 1951, 8, 206.

\title{
THE WORLD HEALTH ORGANIZATION AND OCCUPATIONAL HEALTH
}

\author{
BY \\ SVEN FORSSMAN
}

Lately Consultant on Social and Occupational Health, WHO

It is necessary to have some general knowledge of the work of the World Health Organization (WHO) to understand the position of occupational health within its programme. For this reason a general survey of the work of WHO will be given in the first part of this article, and the second part will deal with occupational health problems.

\section{Survey of Work by WHO}

To deal with special problems, the United Nations have organized several specialized agencies such as FAO for food and agricultural problems, UNESCO for education, and WHO as the specialized agency responsible for health problems.

WHO began its activities on an interim basis in 1946 , and when the required number of countries had ratified the Constitution in April, 1948, WHO began work on a permanent basis.

The objective of WHO is stated in the Constitution to be " the attainment by all peoples of the highest possible standard of health". Its definition of health is "a state of complete physical, mental and social well-being". The prevention of accidents, and the improvement of working conditions are also specifically mentioned in the Constitution of WHO.

WHO includes a headquarters with a permanent staff, an executive board of 18 members, who meet twice a year to follow up the work of headquarters, and an assembly which meets annually to decide the general principles of the organization's work, budget problems and other issues. The headquarters, which is in Geneva, is organized in three departments, which, in turn, are divided into divisions and sections. For the field activity, WHO has divided the world into six regions with regional offices. There is one office for Europe, one for Africa, one for the Middle East with its office in Alexandria, one for South East Asia with an office in New Delhi, one for the American continents where the Pan-American Sanitary Bureau serves as the regional office in Washington, and one region for the Western Pacific where the office will, this year, be permanently established in Manila. There is at present in WHO a tendency to decentralize activity from the headquarters to the regional offices.

The work of WHO may be divided into two main parts : the collecting and compiling of information which is then distributed by various means, and the field work and other activities the function of which is to solve theoretical and practical health problems in various parts of the world.

Much of the information thus collected deals with causes of deaths, epidemics, etc. An international nomenclature on the causes of death has been issued by WHO ; new international regulations for quarantine for epidemic diseases have been adopted this year by the World Health Assembly. The section on biological standardization proposes suitable international standards on antibiotics or drugs, and an international pharmacopoeia will be printed this year on the basis of work done at WHO headquarters and by one of its committees of experts.

The information collected and compiled by WHO will be distributed all over the world through several publications: the WHO News-Letter, which is in a somewhat popular form, and the more scientific Bulletin of WHO and Chronicle of WHO, as well as the weekly Epidemiological Record and the Epidemiological and Vital Statistics Report. WHO is also sending out daily reports by radio on the situation of epidemic diseases in different parts of the world, and this is of great importance to those operating air and sea travel.

Almost every section at headquarters has available a group of experts who can give the necessary information on special problems within each section's scope. A certain number of these experts may form a committee of experts to deal with theoretical health problems, and the reports of these committees provide useful information. There are committees of experts, for instance, dealing with biological standardization, insecticides, 
tuberculosis, and mental health. When two specialized agencies have a common interest in a field, a joint committee of experts may be created as, for instance, the Joint FAO/WHO Committee on Nutrition, or the two Joint ILO/WHO Committees on the Hygiene of Seafarers, and on Occupational Health.

On request from a country WHO may begin field work to solve some practical health problem in that country. This may be done by sending experts or groups of experts as consultants or to demonstrate the application of certain health methods. Demonstration areas or health centres may be organized where field work can be done and, at the same time, local health personnel may be trained.

One of the main obstacles to the raising of health standards is, in many countries, the lack of trained personnel. To educate and train health personnel in various countries is one of the most important tasks of the organization. This may be done not only in demonstration areas in the respective countries, but also through fellowships or travel grants to doctors, engineers or nurses for studies at foreign universities, or for travel in other countries. International seminars on health problems, at which a number of highly qualified people can discuss one or several health problems from different points of view, are very effective in stimulating interest and exchanging accounts of experiences. Reports from such seminars provide valuable information on the present situation of the health problems discussed from the research and practical points of view.

When WHO began its activities, it was decided that certain health problems should have priority within the work of WHO, namely, tuberculosis, venereal disease, malaria, malnutrition, and maternal and child health. The activity of the organization has since expanded considerably. Mental health, for example, has been added to the subjects to be actively supported, and in 1950 a section on social and occupational health was established within the Division of the Organization of Public Health Services.

\section{Occupational Health Problems}

The earlier international work on occupational health is important. The main objective of the permanent International Commission on Industrial Medicine, founded in 1905, was the organization of international congresses of which the last two were the Ninth International Congress held in London in 1948, and the Tenth held in Lisbon this year.

The International Labour Office has, since 1920, been working in the field of occupational health, and has been chiefly concerned with accidents and occupational diseases. Its activities have included the organization of international conferences, the issuing of an excellent bibliography of occupational medicine, monographs on special problems of occupational health etc.

It is obvious that the work on social and occupational health by WHO must be closely coordinated with the activity of ILO, and in this connexion, in 1948, the first Assembly of WHO decided to set up a Joint ILO/WHO Experts Committee for Occupational Health. This Committee, which first met in September, 1950, consisted of the following members: Sir Joseph Bhore (India) ; Professor Luigi Carozzi (Switzerland) ; Dr. Leonard Greenburg (U.S.A.) ; Dr. Branko Kesic (Yugoslavia); Professor Pierre Mazel (France) ; Dr. E. R. A. Merewether (United Kingdom) ; Dr. Leo Noro (Finland) ; Dr. Ismael Urbandt (Argentina) ; Dr. A. Uytdenhoef (Belgium).

The nomenclature and definition of occupational health varies in different countries. According to a very narrow definition, occupational health deals only with diseases or injuries caused by conditions of work, that is to say occupational diseases and accidents. According to a broader definition, on the other hand, occupational health includes preventive medicine and medical care for the workers and their dependants. This means that occupational health would, in practice, include all medical activities. The Joint ILO/WHO Committee of Experts devoted much time at its first meeting to a discussion of the terminology and definition of occupational health. The Commission proposed that the term " occupational health" (médicine du travail, medicina del trabajo) should be used. It was agreed that oscupational health should aim at " the promotion and maintenance of the highest degree of physical, mental and social well-being of workers in all occupations; the prevention amongst workers of diseases caused by their working conditions; the protection of workers in their employment from risks to health; the placing and maintenance of the worker in an occupational environment adapted to his physiological and psychological equipment, and, to summarize : the adaptation of work to man, and of each man to his job". This definition gives a very logical limitation to the field of occupational health which will include all the workers' health problems in relation to their working conditions or their employment. Occupational health will thus not only include occupational diseases and accidents, but the application of preventive medicine to industries or other places of employment confronting problems such as the prevention of tuberculosis and other airborne infections, the promotion of mental health and 
prevention of neurosis, the rehabilitation of workers disabled by disease or injury, the placement of workers, routine and special periodic examinations and, finally, health problems affecting special groups such as young persons, women, and, in the western hemisphere, the elderly worker.

A close liaison between WHO and ILO will avoid overlap, and allow each body to follow the other's activities. While WHO followed with interest the ILO's work on accidents and occupational diseases, it would most usefully make studies in other fields of occupational health such as airborne infection, mental health, and geriatrics where it has the necessary experts and experience.

After some preparatory studies by Dr. G. R. Hargreaves, following a request from the Scandinavian countries for information on programmes for mental health in industry, WHO, in 1950, sent Dr. R. F. Tredgold, an English psychiatrist, to spend six weeks in Finland, Sweden, and Norway to study industrial medicine and discuss mental health problems in industry. As a result of this mission, a short course in human relations in industry has, this year, been arranged in England for the benefit of the Scandinavian countries. During this course, these problems were discussed from different points of view by industrial physicians, psychiatrists, psychologists, social workers, industrial managers, and workers, who reported on English, and Scandinavian experiences.

WHO may organize seminars or issue monographs on important problems within the field of occupational health. (It is also important to stress the occupational health point of view at seminars or expert meetings dealing with problems allied to occupational health.) A seminar for sanitary engineers held at The Hague in 1950 was arranged by WHO, the International Health Division of the Rockefeller Foundation, and the Government of the Netherlands. (At this seminar lectures were also given by a physician and an industrial hygiene engineer to inform the members present of basic problems of occupational health.)

The information services such as indexing, abstracting, or reviewing articles by ILO and WHO are already coordinated.

In the future several practical problems within occupational health will be considered by WHO. These problems include the promotion of health in small industries, the arrangement of part-time work for housewives working in industry, and occupational health problems in different climates.

Many practical problems also arise within the United Nations programme for the Technical Assistance for Economic and Social Development of Underdeveloped Countries. As it is useful simultaneously to develop the industries and the industrial health services in a country, it is clear that there are many important occupational health problems connected with this programme.

One of the main obstacles in raising health standards of people is the lack of trained personnel. WHO has supported this training by offering fellowships to different countries. During 1947 to 1950 , in the field of occupational health, 13 longterm fellowships have been given to doctors and engineers.

It is thus made clear that occupational health is part of the responsibility of the World Health Organization and will be developed, in cooperation with ILO, as part of the programme of this organization.

\section{Summary}

A short survey is given on the general activity of WHO, the specialized agency for health problems of the United Nations. The scope of occupational health is discussed, and a survey of present and future activity of WHO in the field of occupational health is given. 